\title{
PERWUJUDAN KAMPUNG BUDAYA DI NAGARI JAWI JAWI KECAMATAN GUNUNG TALANG KABUPATEN SOLOK PROPINSI SUMATERA BARAT
}

\author{
Admiral \\ Febri Yulika \\ Anak Agung Istri Agung Citrawati \\ Safara Fitri Rahmatika \\ Program Studi Seni Karawitan-Prodi Antropologi Budaya \\ Fakultas Seni Pertunjukan -ISI Padangpanjang \\ Jl. Bahder Johan No.35 Padangpanjang 27128. \\ Padangpanjang-Sumatera Barat \\ febriisipp@gmail.com \\ citrawatiaa1968@gmail.com
}

\begin{abstract}
ABSTRAK
Nagari Jawi Jawi merupakan salah satu daerah yang memiliki potensi seni, budaya dan sastra yang sangat kaya. Hal ini dibuktikan dengan geliat aktivitas sanggar-sanggar seni budaya yang dilaksanakan hampir setiap bulannya. Agar Nagari Jawi Jawi menjadi Kampung Budaya dapat berkembang dan menjadi tujuan wisata alternatif, maka perlu adanya perhatian seperti dari pemerintah daerah, perguruan tinggi dan pihak swasta untuk membantu mengembangkan potensinya. Target yang ingin dicapai dari pelaksanaan program ini bagi masyarakat Nagari Jawi-Jawi yang nantinya akan menjadi kampung budaya adalah Jasa dan Pelatihan. Pendekatan yang dilaksanakan untuk membantu mitra dalam hal ini adalah Masyarakat Nagari Jawi Jawi dalam usaha perwujudkan Nagari Kampung Budaya dilakukan dalam bentuk metode penyuluhan dan pelatihan yang dilaksanakan dengan Metode Ceramah dan Demontrasi.
\end{abstract}

Kata Kunci : Nagari jawi Jawi; Kampung Budaya. 


\section{PENDAHULUAN}

Indonesia adalah Negara kepulauan yang memiliki keanekaragaman etnik atau suku bangsa dan budaya, serta kekayaan di bidang seni, budaya dan sastra yang secara keseluruhan merupakan potensi nasional. Salah satu ragam daerah yang memiliki kekayaan seni, budaya dan sastra adalah Kabupaten Solok yang berada di Provinsi Sumatera Barat.

Secara geografis letak Kabupaten Solok berada antara $00^{\circ} 32^{\prime}$ $14^{\prime \prime}$ dan $01^{\circ} 46^{\prime} 45^{\prime \prime}$ Lintang Selatan dan $100^{\circ} 25^{\prime} 00^{\prime \prime}$ dan $101^{\circ} 41^{\prime} 41^{\prime \prime}$ Bujur Timur. Topografi wilayahnya sangat bervariasi antara dataran, lembah dan berbukit-bukit, dengan ketinggian antara 329 meter - 1458 meter di atas permukaan laut. Nagari Jawi-jawi merupakan salah satu nagari yang terdapat di kecamatan Gunung Talang, Kabupaten Solok. Nagari Jawi-jawi memiliki luas sekitar 149 Km2, dengan kondisi geografis memiliki suhu udara rata-rata ${ }^{20} \mathrm{C}$. Secara administrasi pemerintahan, nagari
Jawi-jawi dibagi menjadi empat jorong, yaitu : jorong Balai Oli, jorong Pakan Jumat, jorong Tangah Padang, dan jorong Pinang Sinawa. Menurut data Hal|59 nagari tahun 2016, jumlah penduduk secara keseluruhan sekitar 3253 jiwa dari 954 Kepala Keluarga. Letak nagari Jawi-jawi secara geografis berada di dataran tinggi yaitu sekitar kaki gunung Talang membuat nagari Jawijawi memiliki udara yang sejuk sehingga masyarakat dominan memiliki mata pencaharian sebagai petani atau berladang.

Nagari Jawi Jawi merupakan salah satu daerah yang memiliki potensi seni, budaya dan sastra yang sangat kaya. Hal ini dibuktikan dengan geliat aktivitas sanggar sanggar seni budaya yang dilaksanakan hampir setiap bulannya. Adapun beberapa seni budaya yang sampai saat ini masih dilestarikan di nagari ini seperti, Randai, Tari Tradisi Minangkabau, Pasambahan Minangkabau, Silat Minangkabau dan lainnya. Melihat banyaknya seni tradisi yang ada di masyarakat tersebut maka masyarakat 
dan pemerintah Kabupaten Solok melalui Wali Nagari dan jajarannya berusaha menciptakan sebuah Kampung Budaya yang nantinya akan memberikan efek positif bagi perkembangan daerah dan sumber daya manusia serta ekonomi di Nagari jawi Jawi.

Selama ini upaya-upaya yang dilakukan oleh masyarakat Jawi Jawi dalam perwujudan kampung budaya di antaranya adalah dengan membentuk sanggar kesenian yang bertujuan untuk melestarikan kesenian tradisional seperti tari-tarian dan seni pertunjukan, untuk permainan anak kegiatan pelestarian dilakukan dengan cara membudayakan kembali anakanak di kampung budaya untuk melakukan permainan- permainan tradisional. Sedangkan untuk melestarikan budaya yang sifatnya kemasyarakatan seperti budaya gotong royong mereka melakukan kegiatankegiatan pada waktu tertentu yang melibatkan seluruh warga.

Kegiatan lain yang dilaksanakan dalam rangka pelestarian budaya dan memperkenalkan keberadaan kampung budaya ini adalah dengan cara menyelenggarakan festival budaya. Kegiatan ini dilaksanakan satu tahun Hal|60 sekali. Kegiatan tahunan ini dirasakan masih kurang sehingga masyarakat dikampung budaya menganggap perlu adanya keberlanjutan upaya memperkenalkan budaya- budaya yang ada. Kegiatan-kegiatan yang inten dalam upaya pelestarian buadaya dapat terwujud dengan baik apabila budaya yang dilestarikan di kampung ini dapat dipertunjukan seiring dengan kunjungan wisatawan. Upaya ini akan mendorong pada terciptanya pelestarian budaya yang lebih baik dan sekaligus memberikan nilai manfaat lebih. Sehingga tujuan kampung budaya sebagai kampung pelestari budaya sekaligus menjadi tujuan wisata alternatif dapat tercapai.

Selama ini jumlah kunjungan wisatawan ke Jawi Jawi sebagai perwujudan kampung budaya belum signifikan. Hal ini berkaitan erat dengan kurangnya informasi dan promosi mengenai keberadaan 
kampung. Bentuk kunjungan yang telah terselenggara kekampung budaya di antaranya adalah kunjungan beberapa sekolah dan kunjungan perorangan. Padahal secara infografis Pariwisata bahwa Kab. Solok merupakan salah satu destinasi wisata alam yang terbaik di Provinsi Sumatera Barat.

Pemerintah Daerah Kabupaten Solok berbenah dan langsung melakukan inovasi dengan menetapkan Nagari Jawi Jawi sebagai Kampung Budaya Wisata. Kementerian Pariwisata Republik Indonesia pun menyebutkan bahwa Nagari Jawi-Jawi Guguk, Kecamatan Gunung Talang, Kabupaten Solok masuk dalam 10 desa prioritas untuk dijadikan desa budaya pembinaan pariwisata di Indonesia. Kampung budaya merupakan salah satu implementasi untuk pelestarian nilai-nilai tradisi, kebudayaan lokal dan kesenian anak nagari. Kita sangat memahami bahwa di nagari ini sangat banyak budaya baik yang perlu kita lestarikan. Sebagai destinasi wisata budaya, tentunya kita perlu berbenah diri, seperti halnya kebersihan, keramahan dan kenyamanan bagi para wisatawan yang akan datang dan jaga nama nagari.

\section{Permasalahan Mitra}

Masyarakat di Nagari Jawi Jawi menyadari adanya potensi seni, budaya dan wisata yang dapat dijual tetapi mereka belum paham bagaimana mengemas dan mengelola potensi yang ada menjadi sebuah produk wisata yang memiliki nilai jual dan memberikan nilai ekonomi. Mereka belum memahami dengan baik apa saja yang harus disiapkan dalam mengelola kampung mereka untuk menjadi kampung tujuan wisata. Selain itu keterbasan mereka dalam membiayai promosi keberadaan dan kegiatan-kegitan budaya yang dilaksanakan dikampung budaya membutuhkan sarana promosi yang murah namun memiliki jangkauan yang luas seperti memanfaatkan sarana internet untuk melakukan promosi. 
Agar Nagari Jawi Jawi Menjadi Kampung Budaya dapat berkembang dan menjadi tujuan wisata alternatif maka perlu adanya perhatian seperti dari pemerintah daerah, perguruan tinggi dan pihak swasta untuk membantu mengembangkan potensinya. Oleh karena itu perlu dilakukan pelatihan guna meningkatkan kemampuan SDM yang ada dalam mengelola dan menciptakan nilai jual kampung budaya, memberikan pelayanan yang baik dan mempromosikan keberadaan kampung budaya secara luas. Sehingga diharapkan budaya Minang kabau dapat dilestarikan sekaligus dapat memberikan nilai ekonomis yang pada akhirnya bisa meningkatkan pendapatan masyarakat.

$$
\text { Berdasarkan beberapa }
$$

permasalahan tersebut di atas, maka perlu untuk melalukan pemberdayaan masyarakat melalui Pengembangan Kampung Budaya sebagai destinasi wisata melalui peningkatan sumber daya masyarakat dalam bidang kesenian, peningkatan manajerial pertunjukan kesenian dan publikasi promosi melalui publikasi masa dan media sosial. Intinya adalah pelaksanaan pemberdayaan Hal| 62 masyarakat ini "transfer of knowledge" dari Perguruan tinggi ke Masyarakat.

Pendekatan yang dilaksanakan untuk membantu mitra dalam hal ini adalah masyarakat Nagari Jawi jawi dalam usaha perwujudkan Nagari Kampung Budaya dilakukan dalam bentuk metode penyuluhan dan pelatihan yang dilaksanakan dengan cara berikut :

\section{Metode Pelaksanaan Pengabdian \\ 2.1 Metode Ceramah}

Memberikan sosialisasi dan workhop pentingnya pengelolaan manajerial seni pertunjukan

Memberikan sosialisasi dan workshop peningkatan promosi dan publikasi melalui media On Line seperti, Web, Blog, Fan Fage dan Media Online Lainnya. 


\subsection{Metode Demontrasi / Praktek}

Metode demontrasi atau praktek ini bertujuan memberikan peningktan kualitas seni pertunjukan dalam hal ini Randai, Indang dan Tari Tradisi dalam usaha meningkatan kualitas seni pertunjukan di nagari jawi jawi Kabupaten Solok.

Kampung Budaya sebagai manifestasi perwujudan pelestarian seni dan budaya khususnya seni tradisi di Sumatera Barat merupakan sebuah kewajiban yang harus dilestarikan oleh insan intelektual seni khususnya dosen Institut Seni Indonesia Padangpanjang dalam bentuk sebuah pelaksanaan pengabdian masyarakat. Dalam usaha perwujudan kampung budaya tersebut maka pengabdian yang dilakukan oleh tim pengabdi di nagari Jawi Jawi Kab Solok antara lain :

\section{Optimalisasi Seni Tradisi dalam}

\section{Wujud Peningkatan Kualitas}

\section{Pertunjukan}

Optimalisasi Seni Tradisi khususnya di Nagari Jawi Jawi Kabupaten Solok Selatan yang memiliki potensi seni di bidang Randai dan Indang Padusi yang telah dilaksanakan oleh Tim Pengabdi Antara lain :

- Melaksanakan peningkatan kualitas Latihan Randai dan Indang Padusi

Pelaksanaan peningkatan kualitas latihan randai dan Indang Padusi di Nagari Jawi Jawi yang telah dilaksanakan oleh Tim Pengabdi adalah sebanyak 3 Kali Turun kelapangan. Hal ini bertujuan agar ilmu yang diperoleh tim pengabdi di tingkat perguruan tinggi dapat diaplikasikan di tengah tengah masyarakat

Secara Detail maka proses peningkatan kualitas latihan randai dan Indang Padusi dapat di tampilkan pada tabel 1 di bawah ini : 
Admiral, Febri Yulika, Anak Agung Istri Agung Citrawati,Safara Fitri Rahmatika

\begin{tabular}{|c|l|l|l|}
\hline NO & \multicolumn{1}{|c|}{$\begin{array}{c}\text { Jadwal } \\
\text { Pengabdian }\end{array}$} & \multicolumn{1}{|c|}{$\begin{array}{c}\text { Pengabdian Yang } \\
\text { dilaksanakan }\end{array}$} & \multicolumn{1}{c|}{$\begin{array}{c}\text { Luaran yang } \\
\text { dicapai }\end{array}$} \\
\hline 1 & $\begin{array}{l}\text { Kamis, } \\
\text { Agustus } \\
2018\end{array}$ & $\begin{array}{l}\text { Peningkatan Kualitas } \\
\text { Latihan Randai Anak } \\
\text { Nagari Jawi Jawi }\end{array}$ & $\begin{array}{l}\text { Meningkatnya } \\
\text { kemampuan Randai } \\
\text { anak Nagari Jawi } \\
\text { Jawi }\end{array}$ \\
\hline 2 & $\begin{array}{l}\text { Kamis, 16 } \\
\text { Agustus } \\
2018\end{array}$ & $\begin{array}{l}\text { Peningkatan Kualitas } \\
\text { Latihan Indang Padusi } \\
\text { Anak Nagari Jawi Jawi }\end{array}$ & $\begin{array}{l}\text { Meningkatnya } \\
\text { kemampuan Indang } \\
\text { Padusi anak Nagari } \\
\text { Jawi Jawi }\end{array}$ \\
\hline 3 & $\begin{array}{l}\text { Sabtu, } \\
\text { Agustus } \\
2018\end{array}$ & $\begin{array}{l}\text { Pelaksanaan Julo-Julo } \\
\text { Randai }\end{array}$ & $\begin{array}{l}\text { Penampilan Randai } \\
\text { dari 3 Nagari } \\
\text { Sekitar di Nagari } \\
\text { Jawi Jawi }\end{array}$ \\
\hline
\end{tabular}

Beberapa Dokumentasi

Pelaksanaan Latihan Randai di Nagari Jawi Jawi pada pelaksanaan pengabdian ini adalah sebagai berikut

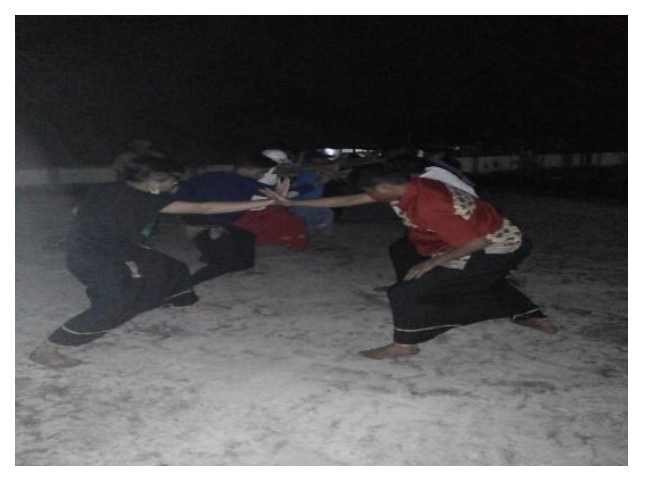

Gambar 1.

Proses Pelaksanaan Latihan Randai (Photo Admiral : Agustus 2018)

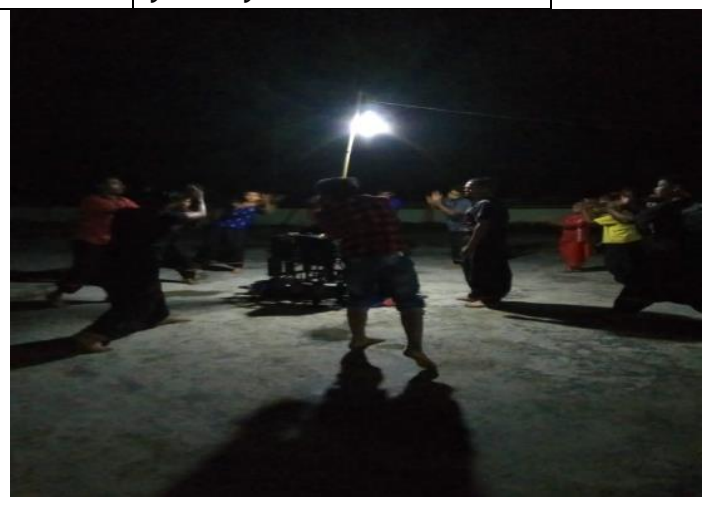

Gambar 2.

Proses Pelaksanaan Latihan Randai (Photo Admiral : Agustus 2018)

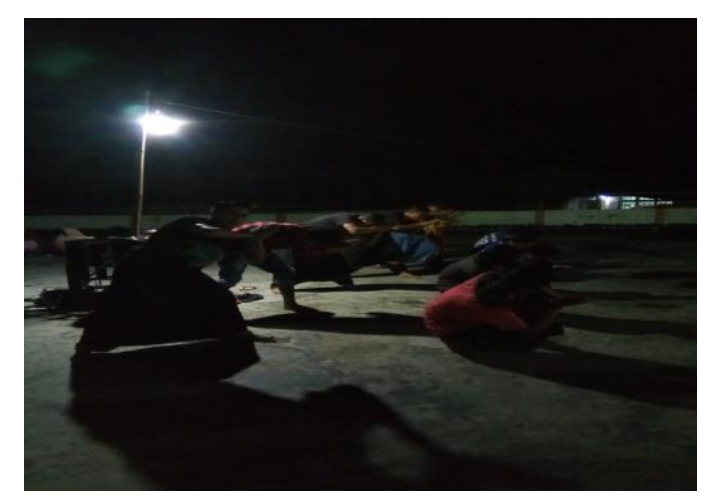

Gambar 3.

Proses Pelaksanaan Latihan Randai (Photo Admiral : Agustus 2018) 


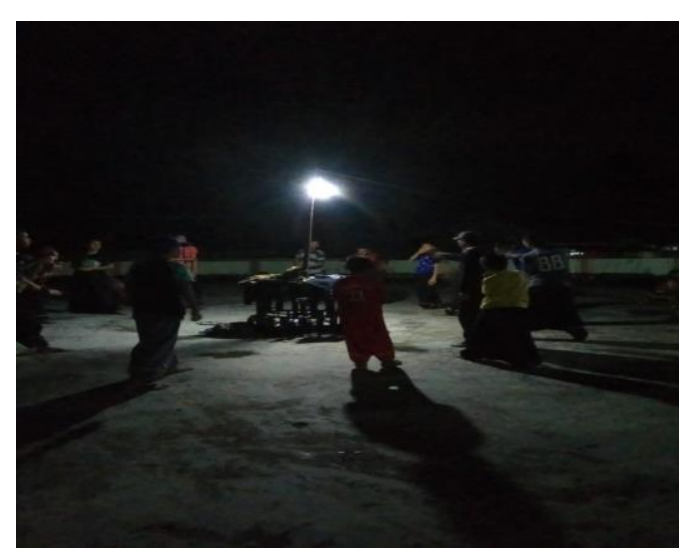

Gambar 4.

Proses Pelaksanaan Latihan Randai

(Photo Admiral : Agustus 2018)

\section{- Melaksanakan peningkatan}

manajerial latihan Randai dan

\section{Indang Padusi}

Pelaksanaan

peningkatan

manajerial dalam hal ini adalah

melakukan transfer ilmu

tentang pertunjukan seni tradisi

dalam hal ini Randai dan indang

padusi di nagari jawi jawi

kabupaten Solok. Aplikasi

sederhana yang dilakukan

adalah bahwa latihan seni

tradisi yang selama ini di kelola

dengan sederhana maka dengan

sedikit sentuhan kreativitas

dapat dijadikan sebagai sebuah

kebiasaan dan sebagai akar

budaya nagari. pengaplikasiannya tersebut

dapat dapat bentuk :
1. Latihan

dilaksanakan

Kesenian

sebagai

sebuah pertunjukan wisata.

Dalam hal ini latihan randai

dan indang yang hanya

dilakukan oleh masyarakat

secara konvensional di

Kampungnya, maka mulai

kedepannya pelaksanaan

latihan

tersebut

dipublikasikan melalui grup-

grup media sosial dan di

publish secara umum.

Sehingga warga disekitaran

nagari jawi jawi tertarik

untuk datang dan melihat

serta terjun langsung dalam

latihan randai dan indang

tersebut.

Secara tidak langsung seni

tradisi yang ada di Nagari 
Jawi Jawi tersebut menjadi daya tarik sebagai perwujudan Nagari Jawi Jawi sebagai kampung budaya dan dapat dijadikan sebagai bentuk wisata tradisi di kabupaten Solok.

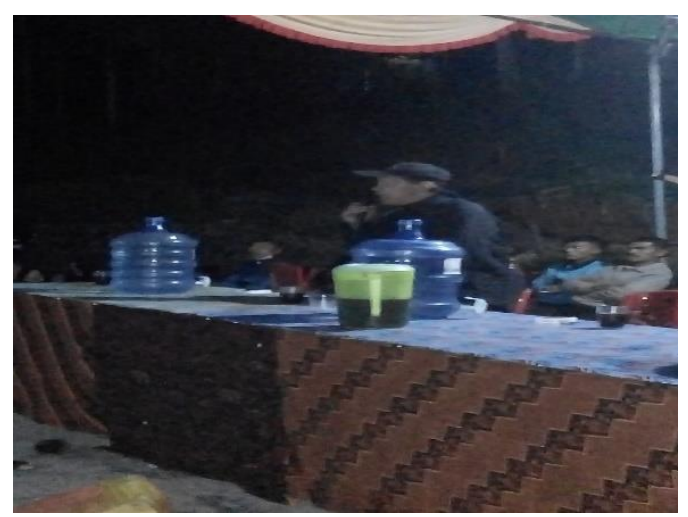

Gambar 5.

Proses Pelaksanaan Workshop/ Arahan lapangan dalam Peningkatan Kualitas Manajerial Seni Pertunjukan

(Photo Admiral : Agustus 2018)

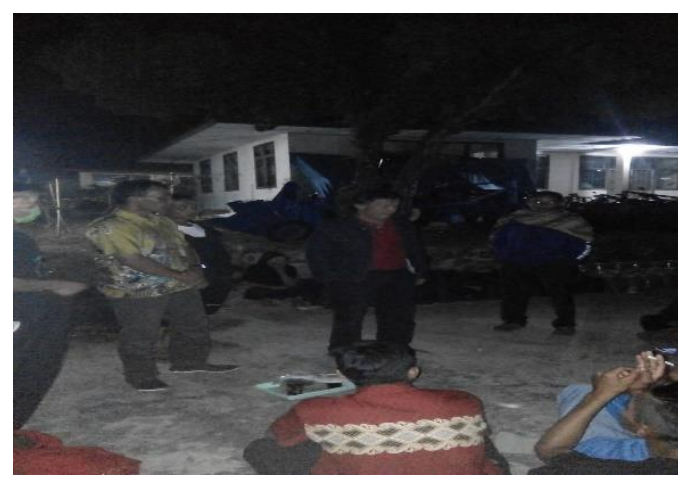

Gambar 6.

Proses Pelaksanaan Workshop/ Arahan lapangan dalam Peningkatan Kualitas Manajerial Seni Pertunjukan (Photo Admiral : Agustus 2018)

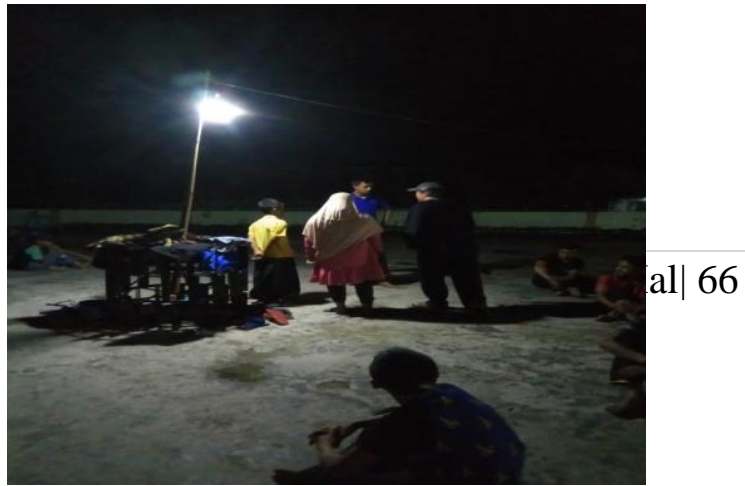

Gambar 7.

Proses Pelaksanaan Workshop/ Arahan lapangan dalam Peningkatan Kualitas Manajerial Seni Pertunjukan

(Photo Admiral : Agustus 2018)

\section{Publikasi Latihan Seni}

\section{Tradisi (Randai dan Indang}

\section{Padusi)}

Publikasi latihan ini merupakan salah satu cara meningkatkan kemampuan manajerial sebuah grup atau sanggar dalam usaha melibatkan masyarakat umum dalam proses pelaksanaan latihan. Latihan yang selam ini dilaksanakan oleh group itu sendiri maka kedepannya latihan kesenian seni tradisi ini dipublikasikan dan dapat dijadikan sebagai sebuah seni pertunjukan. 


\section{Jurnal Batoboh, Vol 4, No1, Maret 2019}

Admiral, Febri Yulika, Anak Agung Istri Agung Citrawati,Safara Fitri Rahmatika

Bukan hanya penampilan akhir saja yang dinikmati oleh masyarakat akan tetapi masyarakat sekitar terlibat dalam pelaksanaan latihan tersebut.

Masyarakat dalam hal ini dapat diartikan masyarakat disekitaran nagari jawi jawi bahkan masyarakat di kab solok dan lebih luasnya publikasi ini akan bersifat nasional

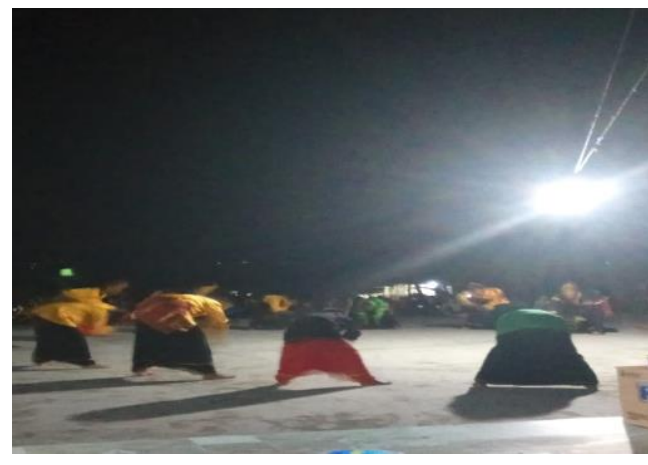

Gambar 7.

Proses Pelaksanaan Julo Julo Randai di nagari Jawi Jawi

(Photo Admiral : Agustus 2018)

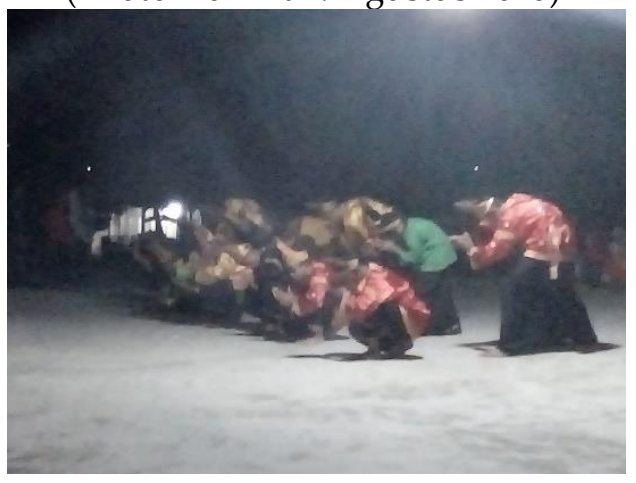

Gambar 8.

Proses Pelaksanaan Julo Julo Randai di nagari Jawi Jawi .

(Photo Admiral : Agustus 2018)

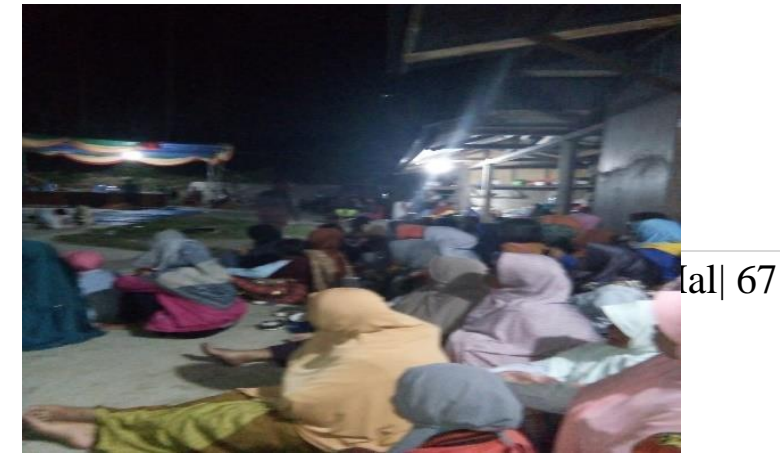

Gambar 9.

Antusias Masyarakat di nagari Jawi Jawi sebagai salah satu efek publikasi dan promosi latihan kesenian (Photo Admiral : Agustus 2018)

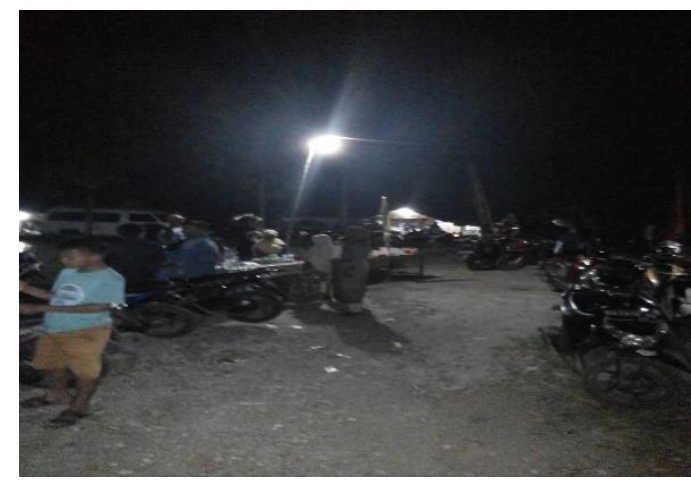

Gambar 10.

Antusias Masyarakat di nagari Jawi Jawi sebagai salah satu efek publikasi dan promosi latihan kesenian (Photo Admiral : Agustus 2018)

\section{SIMPULAN}

Nagari Jawi Jawi merupakan salah satu daerah yang memiliki potensi seni, budaya dan sastra yang sangat kaya. maka perlu untuk melalukan pemberdayaan masyarakat melalui pengembangan kampung budaya sebagai destinasi wisata melalui peningkatan sumber daya 
masyarakat dalam bidang kesenian, peningkatan manajerial pertunjukan kesenian dan publikasi promosi melalui publikasi masa dan media sosial. Intinya adalah pelaksanaan pemberdayaan masyarakat ini "transfer of knowledge" dari Perguruan tinggi ke Masyarakat.

\section{KEPUSTAKAAN}

Direktorat Riset dan Pengabdian Masyarakat (2017). Pedoman Penelitian dan Pengabdian Kepada Masyarakat Edisi X 2017. Jakarta.

Akmal. Laporan Pelaksanaan KKN Tematik Revolusi Mental 2017 ISI Padangpanjang 